\title{
A VIAGEM SEM VOLTA DE JOSÉ ALFERES EM “O CONVIDADO”, DE MURILO RUBIÃO
}

\author{
Márcio Amieiro Nunes* \\ Altamir Botoso ${ }^{* *}$
}

RESUMO: Neste artigo, analisamos o conto “O convidado" de Murilo Rubião, abordamos os principais elementos da narrativa, com ênfase ao tempo e ao espaço. Apoiamo-nos, para isso, nos críticos Moisés (2007), Reuter (2002) e Lins (1976), a fim de classificar os recursos utilizados no conto. Porém, é com base nas epígrafes que abrem cada obra do contista mineiro, que direcionamos a nossa análise, pois elas podem nos ajudar a refletir sobre o sentido final do texto. Também destacamos algumas intertextualidades encontradas em determinados personagens da mitologia grega e, para finalizar, comparamos a obra de Murilo Rubião ao mito de Sísifo, com base nas versões encontradas em Hacquard (1996) e Grave (1955).

PALAVRAS-CHAVE: Conto; Fantástico; Intertextualidade; Mitologia grega; Murilo Rubião.

\section{Introdução}

O conto "O convidado" de Murilo Rubião foi publicado em 1974, como parte do livro intitulado com o mesmo nome, o qual continha mais oito contos inéditos. Os acontecimentos estranhos começam a acontecer desde o início do conto.

José Alferes recebe um convite, porém, sem data e local de onde seria a festa, tampouco contém o nome de quem o havia enviado. A única informação é quanto à vestimenta que deveria ser usada. A princípio Alferes acha que foi uma brincadeira e quase joga o convite fora, mas quando lembra de sua vizinha Débora, por quem ele tem uma certa atração, decide ir, pois julgou que ela the tinha enviado o tal convite.

Em frente à casa de Alferes há uma loja de roupas, onde ele consegue um traje e as informações necessárias para ir à festa. O dono da loja ainda recomenda que ele procure por Faetonte, um taxista conhecedor do caminho para o local da festa. Quando Alferes já

\footnotetext{
${ }^{*}$ Mestrando em Letras pela Universidade Estadual de Mato Grosso do Sul (Uems).

${ }^{* *}$ Doutor em Letras pela Universidade Estadual Paulista Júlio de Mesquita Filho (Unesp). Professor da Universidade Estadual de Mato Grosso do Sul (Uems).
} 
estava vestido para ir, descobre que Débora não lhe enviou o convite, pois ela havia viajado de férias. Mesmo decepcionado, decide ir à festa misteriosa.

Após chegar ao local, Alferes é recepcionado e informado que quando chegasse $o$ convidado especial, a festa se iniciaria. Ao entrar no salão de festas, José Alferes sente-se muito incomodado, principalmente com o assunto das conversas. Nisto, ele conhece Astérope, a quem pergunta pelo convidado, mas, para todas as suas perguntas, as respostas são evasivas.

Com medo, ele foge agoniado e tenta voltar para casa. Faetonte, nega-se a levá-lo para casa naquele momento, e informa que ele deveria esperar pelo convidado. Aborrecido e impaciente, Alferes tenta ir andando até a cidade mais próxima, porém, após vários incidentes, acaba de volta ao local da festa. Na recepção, em meio ao seu desconsolo por não conseguir ir embora, Astérope toca-lhe no braço e o conduz a um caminho desconhecido.

Várias dúvidas são deixadas pelo caminho, sinalizando tratar-se de uma narrativa fantástica. Segundo Todorov (1981), há expressões que são comuns ao gênero fantástico, algumas delas podemos encontrar em "O convidado", a fim de transmitir essa incerteza e ambiguidade das ações. Observe:

Os seus olhos brilhavam como se umedecidos pela neblina que começava a cair. (RUBIÃO, 2000, p. 5)

Astérope olhou-o fixamente, como se pretendesse descobrir nele algo que ainda não decifrara. (RUBIÃO, 2000, p. 5)

Além do desagrado de saber que mais tarde ela estaria deitada com outro, algo de inquietante emanava de Astérope. (RUBIÃO, 2000, p. 5)

Calava a desconfiança, preocupado em descobrir se teria visto uma jovem senhora parecida com ela num quadro, folhinha ou livro. (RUBIÃO, 2000, p. 6)

Aqueles jardins intermináveis, a sua incapacidade de falar a linguagem dos convivas, um convidado cuja ausência retardava a realização da festa. A beleza de Astérope. Agarrou-a pelos ombros, obrigando-a a encará-lo. Seria o brilho dos olhos? Teve medo... (RUBIÃO, 2000, p. 142, grifos nossos)

Todos os sintagmas destacados são reveladores de incertezas e dúvidas, deixando a narrativa cheia de lacunas, instigando o interesse do leitor. Segundo Todorov (1981, p. 43), 
esse procedimento "aparece em quase todos os autores que cultivam o fantástico". Ainda na concepção do autor, "só a linguagem permite conceber o que sempre está ausente: o sobrenatural" (TODOROV, 1981, p. 44). Porém, esse fantástico proposto por Todorov difere do apresentado nas obras de Rubião, as quais se aproximam mais do fantástico moderno. Segundo Carmo (2016, p. 23), o "fantástico contemporâneo está no absurdo. Não há florestas, nem castelos assombrados; apenas o homem em seu cotidiano sufocante". Nesse caso, encontramos essas características em "O Convidado", não há árvores ou animais falantes, mas vemos a personagem em sua agonia sem fim. Sendo assim, pode-se dizer que o conto se enquadra mais no fantástico contemporâneo do que no tradicional.

As obras de Murilo Rubião, segundo Furuzato (2002, p. 19), apresentam uma "reflexão a respeito deste mundo fictício - semelhante ao nosso mundo cotidiano, ao mesmo tempo em que se revela tão absurdo - traria a incerteza sobre aquilo que costumamos considerar verdadeiro, normal, aceitável”. Furuzato (2002), também afirma que as obras de Rubião não se enquadrariam nos estudos de Todorov por se tratar de um fantástico tradicional, enquanto que o fantástico apresentado pelo contista seria o fantástico moderno, conforme vimos anteriormente.

\section{Análise dos elementos da narrativa}

Em uma microanálise do conto destacamos alguns fatores de análise. Segundo Moisés (2007, p. 86), tais fatores englobam "as categorias fundamentais da prosa de ficção" denominadas como microestruturas. Ou seja: "as personagens, o tempo, o lugar, a ação, o ponto de vista narrativo" etc. (MOISÉS, 2007, p. 86).

No conto, a ação é predominantemente externa, pois ocorre no deslocamento de ambientes. Segundo Moisés (2007, p. 89): “uma viagem, o deslocamento de uma sala para outra, o apanhar de um objeto para defesa contra um agressor, e assim por diante, classificam-se como ação externa, que é própria da ficção linear". As ações no conto ocorrem em diferentes locais, que começam no apartamento de José Alferes e terminam no local da festa, veremos outros detalhes mais adiante quando tratarmos da ambientação. 
As personagens no conto, com base na denominação dada por Forster (1949), são todas planas (flat characters), e, Segundo Moisés (2007), são aquelas que não apresentam profundidade, isto é, possuem "um só defeito ou uma só qualidade" e são as mais recorrentes "nos contos, novelas e nos romances lineares" (MOISÉS, 2007, p. 110). Tais personagens "são estáticas por natureza, pois sua característica principal jamais se modifica" (MOISÉS, 2007, p. 111). De acordo com Candido (1964, p. 62), elas permanecem "inalteradas no espírito porque não mudam com as circunstâncias". Para Silva (2011, p. 709), a "personagem plana não altera seu comportamento no decurso do romance e, por isso, nenhum acto ou nenhuma reação da sua parte podem surpreender o leitor”. Percebe-se, portanto, que em "O Convidado" todas as personagens permanecem inalteradas do início ao fim do conto, em virtude de ser uma história curta, não haveria tempo para tais mudanças.

\section{Espaço}

O espaço do conto é “uma metrópole de cinco milhões de habitantes” (RUBIÃO, 2000, p. 1). A ambientação alterna-se entre interna e externa: o apartamento de José Alferes, a loja de roupas e o local da festa, principalmente. Como se trata de uma história urbana, explica Moisés (2007, p. 107), o cenário é “predominantemente o construído pelo homem”.

Com base nesses espaços urbanos, a localização de cada elemento possui uma função. Por exemplo, a janela do quarto de Alferes "dava para uma casa que alugava roupas destinadas a qualquer tipo de solenidade, bailes ou recepções” (RUBIÃO, 2000, p. 1). Tanto a loja, bem como a sua localização têm uma função dentro da narrativa, visto que no convite não havia data de quando seria a festa, esse recurso é utilizado para informar a personagem a possível data do evento. Dessa forma, a freguesia na loja, que normalmente era reduzida, indica a proximidade temporal da festa, devido ao "movimento considerável de pessoas entrando e saindo [da loja], na maioria carregando embrulhos". Caso contrário, "como explicar o procedimento de tanta gente alugando indumentárias especiais nessa época do ano, quando o calendário não indicava nenhuma festividade tradicional?" (RUBIÃO, 2000, p. 1). 
Ora, a única informação dada no convite era em relação ao traje que deveria ser usado pelos cavalheiros no dia da festa: "fardão e bicorne ou casaca irlandesa sem condecorações” (RUBIÃO, 2000, p. 2). Nessa loja, José Alferes percebe a movimentação das pessoas para a aquisição da vestimenta, é nela que Alferes não só consegue alugar seu traje, mas também consegue as informações necessárias para chegar ao local do evento.

O conto começa com características de ambientação franca, de acordo com Lins (1976), é aquela que "se distingue pela introdução pura e simples do narrador", e, em alguns casos, "é levemente mediada pela presença de uma ou mais personagens" (LINS, 1976, p. 79-80). Esse tipo de ambientação é predominante no início do conto, enquanto Alferes prepara-se para a festa, em seu apartamento. A ambientação, no entanto, alterna de franca para reflexa no decorrer do conto, podemos percebê-la no seguinte trecho da obra: "Entraram juntos por um corredor estreito e escuro. De repente, ao abrir-se uma porta larga, deram com um salão fartamente iluminado e repleto de pessoas conversando, rindo, enquanto os garçons serviam bebidas" (RUBIÃO, 2000, p. 4, grifos nossos).

Nota-se um ambiente descrito por um narrador em terceira pessoa de modo objetivo, apenas com o fim de apontar elementos dos locais por onde transita a personagem. Os verbos na terceira pessoa do plural configuram a breve descrição vazia de subjetividade e assinala a passividade da personagem ao adentrar o ambiente. De acordo com Lins (1976, p. 83) a ambientação reflexa "incide sobre a personagem, não implicando numa ação. A personagem, na ambientação reflexa, tende a assumir uma atitude passiva e a sua reação, quando registrada, é sempre interior".

Porém, mais adiante, percebe-se uma mescla na ambientação reflexa com a introdução de ambientação dissimulada. Após "Alferes atravessar sem ser importunado os últimos salões e chegar aos fundos da casa. Uma leve brisa refrescou seu rosto alagado pelo suor. Vinha do parque, onde numerosas pessoas em trajes de passeio se reuniam em bandos dispersos entre árvores e bancos dos jardins” (RUBIÃO, 2000, p. 4, grifo nosso).

$\mathrm{O}$ ambiente exterior da casa onde a personagem estava se aproximando, foi percebido pelo próprio Alferes por meio de "uma leve brisa" que "refrescon seu rosto" suado (RU- 
BIÃO, 2000, p. 4, grifo nosso). De acordo com Lins (1976, p. 84), nesse tipo de ambientação dissimulada, os atos da personagem "vão fazendo surgir o que a cerca, como se o espaço nascesse dos seus próprios gestos”, pode-se dizer, então, que há uma relação dialética entre a personagem e o ambiente.

Por fim, quando Alferes tenta ir sozinho para casa, toda a ação ocorre em um espaço externo e a ambientação apresenta características predominante do tipo dissimulada ou obliqua, conforme o trecho abaixo:

Alferes desceu do carro resmungando, disposto a enfrentar a cerra-
ção. Pelos seus cálculos, bastaria caminhar um quilômetro para che-
gar à parte mais habitada do bairro, onde encontraria condução fácil.
Mal andara cem metros, as dificuldades começaram a surgir. Trope-
çou no meio-fio, indo chocar-se contra um muro. Seguiu encostado
a este durante curto espaço de tempo e logo as mãos feriram-se
numa cerca de arame farpado. Afastando-se dela, teve a impressão
de que se embrenhara num matagal. Daí por diante, perdeu-se. Ia da
direita para a esquerda, avançava, retrocedia, arranhando-se nos ar-
bustos. (RUBIÃO, 2000, p. 6)

Nesse trecho, percebemos que o ambiente é descrito de modo desordenado, conforme as ações da personagem, que caminha a esmo, sem saber que rumo ou direção tomar.

\section{Narrador e focalização}

O narrador, em terceira pessoa, está limitado as percepções da personagem principal. De acordo com a classificação de Reuter (2002, p. 78), é um narrador heterodiegético e perspectiva passando pela personagem, pois "não se sabe o que se passa na cabeça dos outros atores; não se pode, sem justificativa, mudar de lugar; não se conhece o passado de todas as personagens e não se pode antecipar com segurança o futuro", segue o exemplo:

O porteiro pediu-lhe que esperasse: iria comunicar sua chegada ao comitê de recepção. Minutos depois retornava acompanhado de três senhores discretamente trajados. Moveram de leve as cabeças num cumprimento inexpressivo. Examinaram Alferes, do rosto ao vestuário, demonstrando visível insegurança pela dificuldade em reconhecer nele a pessoa esperada. Silenciosos, retrocederam alguns passos, para mais adiante fecharem-se em círculo, as mãos apoiadas nos ombros uns dos outros. Confabulavam. (RUBIÃO, 2000, p. 4) 
O narrador não diz nada além da perspectiva da personagem, não se sabe o que se passava na cabeça do comitê de recepção, tampouco o que eles confabularam, só sabemos juntamente com Alferes, quando um deles conta ao protagonista o que foi decidido entre eles. Segundo Tacca seria o narrador equisciente, uma vez que pode "contar assumindo a consciência e ainda, em muitos casos a presumível linguagem do personagem, aproximando-se dele o mais possível - embora sem lhe dar a palavra" (TACCA, 1978, p. 76 grifo do autor).

Assim, "alternam-se os momentos em que se tem a sensação de se saber, sem meditação, o que se passa no próprio interior da personagem” (REUTER, 2002, p. 78). Podemos perceber esses elementos nos seguintes trechos:

(1) À falta de outros esclarecimentos, julgou tratar-se de alguma festividade religiosa ou de insípida comemoração acadêmica. (RUBIÃO, 2000, p. 1, grifo nosso)

(2) Pensou em jogar fora a carta, só não o fazendo ao lembrar-se de Débora, a estenógrafa, pensionista de um dos apartamentos no mesmo andar do seu. (RUBIÃO, 2000, p. 1, grifo nosso)

(3) Conteve a impaciência, apesar do lento fluir do tempo. [...] Entre um e outro pensamento, tentava relembrar onde vira alguém vestido do mesmo modo. Um rei espanhol ou um desconhecido?. (RUBIÃO, 2000, p. $1-2$, grifo nosso)

Nos trechos (1) e (2), é como se o narrador adentrasse à consciência da personagem e no último (3), percebe-se, ainda, o uso do discurso indireto livre. Portanto, pode-se dizer que o narrador se limita a "uma focalização interna circunscrita a uma personagem" (SILVA, 2011, p. 773, grifo nosso).

\section{Tempo}

O tempo em "O convidado” é cronológico, porém não há uma indicação explícita, o seu decorrer se dá pelo fluir das ações e atos dentro da narrativa. Assim, transmite uma ideia de atemporalidade De acordo com Moisés (2007, p. 102) "o tempo cronológico semelha específico do conto e da novela, e pode ocorrer no romance linear [...]". Nessas obras, afirma Moisés (2007, p. 103) que, “o tempo escoa como se o ficcionista pudesse 
cronometrar todas (ou quase todas) as ações das personagens, minuto a minuto, hora a hora, dia a dia". Assim, "a ideia de tempo é dada pela própria ordenação da história”. No conto, o tempo parece exercer a função de contribuir "para a dramatização da narrativa" (REUTER, 2002, p. 58). Isto é, na festa, enquanto todos esperavam pelo convidado o suspense aumenta, "por exemplo, com o aumento do tempo", pois o convidado nunca chega, porque o tempo não passa (REUTER, 2002, p. 58).

Quanto às anacronias, conforme a classificação de Silva (2011, p. 755), podem ser classificadas como interna, "se a amplitude começa depois do início da diegese da narrativa primária", ou externa "se a amplitude começa e acaba antes do início da narrativa primária". Segundo Silva (2011, p. 751), as anacronias são "os desencontros entre a ordem dos acontecimentos no plano da diegese e a ordem por que aparecem narrados no discurso", e podem aparecer por intermédio de analepses ou prolepses. A primeira, de acordo com Silva (2011, p. 753), ocorre "por recuos no tempo, dá-se em geral a designação de flashback". A segunda "pode consistir, porém, numa antecipação, no plano do discurso, de um facto ou de uma situação que, em obediência à cronologia diegética, só deviam ser narrados mais tarde" e são nomeadas de flashforwards (SILVA, 2011, p. 752).

Em O convidado, encontramos tanto a anacronia interna, por meio da analepse, como a anacronia externa, por meio da prolepse. O flashback ocorre quando o narrador explica algo sobre Débora, a vizinha de Alferes que morava "em um dos apartamentos no mesmo andar que o seu" (RUBIÃO, 1974, p. 1). Nesse caso, a analepse é utilizada como

[...] um recurso de que os romancistas se servem com frequência, porque permite comodamente esclarecer o narratário e/ou o leitor sobre os antecedentes de uma determinada situação - sobre tudo (sic.) quando essa situação se encontra no início da narrativa - e sobre uma personagem introduzida pela primeira vez no discurso ou neste reintroduzida. (SILVA, 2011, p. 752)

Quando Débora é citada pela primeira vez na narrativa, é por meio de uma analepse que o texto recua no tempo para explicar um fato ocorrido, no passado, entre as duas personagens. Nesse trecho, o narrador afirma que Alferes “[...] fizera diversas tentativas de abordá-la e fora repelido. Com um meio sorriso, uma frase reticente, olhava-o furtivamente 
e, sem virar-se para trás, sabia que Alferes ficara parado, o sangue fervendo, a acompanharlhe os passos por toda a extensão do corredor” (RUBIÃO, 1974, p. 1).

É por meio dessa retomada no tempo que o narrador explica o interesse de José Alferes em ir à festa após se lembrar de Débora, e associar o "talhe feminino da caligrafia" do convite com sua vizinha.

A prolepse (flashforward), ocorre em dois momentos, ambos por meio das epígrafes utilizadas por Murilo Rubião em suas obras. No início do livro “O convidado” há a seguinte epígrafe: “Ao sobrevir-lhes de repente a angústia, eles buscarão a paz, e não haverá” (EZEQUIEL, VII, 25 apud RUBIÃO, 2000, p. 4). Essa citação bíblica abre a obra e abrange, de maneira geral, todos os contos que compõem o livro, inclusive o conto "O convidado". Mesmo sendo uma anacronia externa, por estar fora da narrativa principal, podemos relacioná-la a um acontecimento dentro da narrativa que envolve a personagem principal.

Em um dado momento, José Alferes está na festa e, de repente, sobreveio-lhe uma grande angústia, então ele foge, tenta ir embora, mas não encontra o caminho de volta para casa. A casa simboliza paz, refúgio e proteção, mas Alferes não consegue encontrá-la, conforme foi predito na primeira epígrafe.

A outra epígrafe que abre, exclusivamente, o conto "O convidado", caracteriza outra prolepse em mais uma citação bíblica, dessa vez do livro de Jó: "Vê, pois, que passam os meus breves anos, e eu caminho por uma vereda, pela qual não voltarei” JÓ, XVI, 23 apud RUBIÃO, 2000, p. 1). Tal citação, remete ao final do conto em que Alferes, após, sem sucesso, tentar ir para casa, involuntariamente, volta à festa e depois é convidado por Astérope a segui-la em um caminho, provavelmente, sem volta. Nesse caso, Astérope poderia simbolizar a morte, e, quem sabe, aquele talhe feminino da caligrafia que estava no convite era de Astérope, ou seja, ele teria sido convidado pela própria morte.

\section{Intertextualidade e seus elementos mitológicos: semelhanças e diferenças}

Por fim, nesse segundo momento, após as análises da microestrutura da obra, fizemos uma análise mais abrangente que envolve os fatores intertextuais e sociais da obra de Murilo Rubião, “O convidado”. De acordo com Moisés (2007, p. 87), “a macroanálise 
identifica-se antes de tudo pela sua verticalidade, pois anela investigar a esfera dos conceitos, sentimentos e emoções que subjaz ao plano das microestruturas".

As personagens nomeadas no conto são: José, Débora, Faetonte e Astérope. Os dois primeiros são nomes bíblicos e os dois últimos, mitológicos. Outro fator que poderia ser considerado é que o nome José Alferes é a junção do primeiro nome de Tiradentes seguido da patente oficial militar que ele ocupava, isto também remeteria ao mártir mineiro.

$\mathrm{Na}$ mitologia grega, Faetonte é filho do Sol (Hélio), responsável por atravessar os céus, todos os dias, com sua carruagem solar. Um dia, Hélio promete conceder qualquer pedido a Faetonte, a fim de comprovar sua paternidade. Então, Faetonte pede para conduzir a carruagem solar, ao menos por um dia. Seu pai, Hélio, cede à pressão de seu filho e, após várias recomendações, permitiu-lhe conduzi-la. Porém, Faetonte não teve força suficiente para controlar os cavalos, ao desviar-se da rota, se aproximou muito da Terra e queimou boa parte dela. Então, Zeus, a fim de evitar uma catástrofe maior e impedir que a Terra fosse totalmente queimada, atingiu-o com um raio, lançando-o morto no rio Eridano (Pó). A versão aproxima-se da contada em The Greek Myths de Robert Graves (1955).

No conto, Faetonte "era, no setor hoteleiro, o condutor habitual dos que procuravam divertimentos noturnos na cidade" (RUBIÃO, 2000, p. 2). Ele foi o responsável em levar José Alferes à festa, pois sabia o caminho. Ao contrário da personagem mitológica, Faetonte obedece a todas as recomendações dadas a ele, até mesmo quando Alferes pede que ele o conduza ao hotel, o motorista recusa-se e afirma que ele não poderia sair dali enquanto o convidado não chegasse. Alferes tenta convencê-lo de todas as formas, inclusive oferece dinheiro pela corrida, mas mesmo assim, "Faetonte recusou: permaneceria no local, aguardando as determinações da Comissão" (RUBIÃO, 2000, p. 7).

Na mitologia, o pai de Faetonte, Hélio, cede a pressão do filho, que por sua vez não obedece às recomendações dadas pelo seu pai. Estes erros não foram cometidos por Faetonte em "O Convidado". Além de não ceder às pressões, tanto emocionais como financeiras de Alferes, seguiu todas as recomendações dadas pela Comissão da festa.

A outra personagem mitológica é Astérope, uma das sete Plêiades, filha de Atlas e Pleione, seu nome significa "a de aspecto de uma estrela brilhante", conforme o Dicionário 
Etimológico da Mitologia Grega (2017). Astérope assim como as suas irmãs, casou-se com um deus, exceto Mérope que "se casou com Sísifo de Corinto, razão pela qual não fora incluída na constelação, pois Sísifo era um mero mortal” (GRAVES, 1955, p. 270). Segundo Grimal (2005), Sísifo era filho de Éolo, e foi fundador de Éfira, depois conhecida como Corinto. Ele era considerado um homem astuto, tanto que conseguiu escapar da morte por duas vezes, mas quando

[...] Sísifo morreu finalmente, com pena, sem dúvida, de não encontrar novas escapatórias, foi submetido a uma dura prova, eternamente renovada: ele devia empurrar um enorme rochedo, e subir com ele a determinado lugar, mas mal conseguia o feito, o bloco de pedra escapava-lhe e voltava para baixo. Sísifo recomeçava assim, de novo, a empurrar a sua pedra, sem remissão e sem resultado. Ele é o símbolo do homem na sua luta absurda contra um destino obstinado. (HACQUARD, 1996, p. 267)

Em “O Convidado”, José Alferes passa por essa mesma situação, ao fugir da festa tentou ir para casa, porém, teve diversos problemas no caminho, e após se ferir várias vezes,

[...] teve a impressão de que se embrenhara num matagal. Daí por diante, perdeu-se. Ia da direita para a esquerda, avançava, retrocedia, arranhando-se nos arbustos.

Perdera o chapéu de plumas, a roupa rasgara-se em vários lugares, romperam-se as sapatilhas no calçamento irregular dos diversos sítios pelos quais passara. Os pés sangravam. Aflito, buscando na escuridão luz de casa ou de rua que o orientasse, desequilibrou-se e rolou por um declive. Ao levantar-se, avistou bem próximo, frouxamente iluminado, o edifício que há pouco deixara. (RUBIÃO, 2000, p. 6)

Mesmo após tanto esforço, em vão, Alferes volta ao seu estado inicial, ou seja, retorna à festa, tal qual Sísifo, não consegue fugir daquilo que já estava destinado a ele. Depois disso, Astérope o reencontra, na mitologia ela era uma das sete estrelas da Plêiade. As constelações também têm a função de indicar o caminho aos viajantes noturnos, mas, nesse caso, Astérope deixou Alferes ainda mais desorientado e o conduziu, na festa, por um "parque demasiadamente extenso" e “jardins intermináveis". O único caminho que ela o conduziria, seria para um lugar desconhecido. 
O fato de José Alferes perceber algo inquietante em Astérope e sentir medo ao olhar em seus olhos, poderiam ser indícios de que ela era a metáfora da própria morte e o guiaria a uma vereda da qual ele não mais voltaria, ou seja, um caminho desconhecido e provavelmente sem volta, como indica a prolepse no início do conto.

Outra intertextualidade que vale a pena destacar é o momento em que José Alferes está à espera de um convidado que não chega, essa espera nos remete a obra de Samuel Beckett Esperando Godot, em que Estragon e Vladimir esperam por Godot que também nunca chega, tanto a história de Beckett como a de Rubião poderiam ser consideradas uma ficção de temáticas absurdas.

\section{Considerações finais}

A análise que apresentamos neste artigo não significa que seja a única possível, pois nessa mesma obra há outras possibilidades de interpretações, principalmente, quanto às intertextualidades que direcionam os sentidos do texto. As personagens respondem as perguntas de forma evasiva, deixando tanto Alferes, como o leitor em dúvida dos acontecimentos dentro da narrativa, e entre a possível dualidade do mundo real e imaginário. José Alferes, por duas vezes, se confunde com a imagem de um provável rei antigo, mais adiante, vê em Astérope a possível imagem de outra pessoa, há um conflito interno vivido pela personagem que o deixa imerso em meio a perguntas sem respostas.

As escolhas e ações de Alferes são malsucedidas, ele tenta encontrar uma saída, mas não a encontra, percorre caminhos que não levam a lugar algum, como um Sísifo condenado ao eterno trabalho inútil. Esses elementos aproximam a obra de Murilo Rubião ao fantástico contemporâneo e a um cotidiano absurdo em que suas personagens estão inseridas. Portanto, o que realmente importa é que todos esses fatores contribuem para renovar o sentido dado ao texto a cada leitura e releitura e revelam a excelência dos contos de Rubião, que exigem um leitor participante, ativo, para poder interpretar e descobrir os sentidos que se ocultam em sua trama. 


\title{
THE JOURNEY WITH NO RETURN OF JOSÉ ALFERES IN “O CONVIDADO” BY MURILO RUBIÃO
}

\begin{abstract}
In this article, we analyze the short story "O convidado" by Murilo Rubião, we approach the main elements of the narrative, with emphasis on the time and space. For that purpose, we support ourselves in the critics Moisés (2007), Reuter (2002) and Lins (1976), in order to classify the resources used in the tale. However, it is based on the epigraphs that precede each work of the short story writer from Minas Gerais, that we direct our analysis, as they may help us in thinking over to the final meaning of the text. We also highlight some intertextualities found on certain of the characters from Greek mythology and, finally, we compare the work of Murilo Rubião with the myth of Sisyphus, based on the versions found in Hacquard (1996) and Grave (1955).
\end{abstract}

KEYWORDS: Short story; Fantastic; Intertextuality; Greek mythology; Murilo Rubião.

\section{REFERÊNCIAS}

CANDIDO, Antonio. A personagem do romance. In. et al. A personagem de ficção. 2. ed. São Paulo: Editora Perspectiva, 1964.

CARMO, Agnaldo Silva do. O mito de Sísifo e sua representação em O Convidado, de Murilo Rubião. 2016. 95f. Dissertação (Mestrado em Letras) - Linguagem, Cultura e Discurso Área de concentração - Letras, Universidade Vale do Rio Verde de Três Corações, Minas Gerais. 2016. Disponível em: <http://www.unincor.br/images/imagens/2016/dissertacao_agnaldo.pdf $>$. Acesso em: 28 nov. 2019.

FURUZATO, Fábio Dobashi. A transgressão do fantástico em Murilo Rubião. 2002. 182f. Dissertação (Mestrado) - Departamento de Lingüística do Instituto de Estudos da Linguagem, Universidade Estadual de Campinas, São Paulo. 2002. Disponível em: < http://repositorio.unicamp.br/bitstream/REPOSIP/270212/1/Furuzato_FabioDobashi_M.pdf>. Acesso em: 28 nov. 2019.

G.R.I.M.M. Dicionário etimológico da mitologia grega. [DEMGOL - On-line], 2017. Disponível em: <www.demgol.units.it> Acesso em: 05 dez. 2019.

GRAVE, Robert. Os Mitos Gregos. Tradução de Fernando Klabin. 3. ed. Rio de Janeiro: Nova Fronteira, 2018.

GRIMAL, Pierre. Dicionário da mitologia grega e romana. Tradução de Victor Jabouile. 5. ed. Rio de Janeiro: Bertand Brasil, 2005.

HACQUARD, Georges. Dicionário de mitologia grega e romana. Tradução de Maria Helena Trindade Lopes. Rio de Janeiro: Edições Asa, 1996.

LINS, Osman. Lima Barreto e o espaço romanesco. São Paulo: Editora Ática, 1976.

MOISÉS, Massaud. A análise literária. São Paulo: Cultrix, 2007.

REUTER, Yves. A análise da narrativa: o texto, a ficção e a narração. Tradução de Mário Pontes. Rio de Janeiro: DIFEL, 2002. 
RUBIÃO, Murilo. Murilo Rubião: obra completa. São Paulo: Companhia das Letras, 2014. SILVA, Vitor Manuel de Aguiar e. Teoria da literatura. 8.ed. Coimbra: Almedina, 2011.

TACCA, Oscar. As vozes do romance. Tradução de Margarida Coutinho Gouveia. Coimbra: Almedina, 1978.

TODOROV, Tzvetan. Introdução à literatura fantástica. Tradução de Maria Clara C. Castello. 2. ed. São Paulo, 1981.

Recebido em: 04/03/2020.

Aprovado em: 22/04/2020. 